\title{
PROFESSOR BÔCHER'S VIEWS CONCERNING THE GEOMETRY OF INVERSION.
}

BY PROFESSOR EDUARD STUDY.

IN a recent paper (this Bulletin, volume 20, pages 185200, January, 1914), Professor M. Bôcher sets forth what he thinks are sound principles for dealing with geometry, and more especially with the geometry of inversion. Herein I am glad to agree with him. The same and similar principles have been expounded, and applied, in a less elementary (but more comprehensive) manner by myself. Professor Bôcher's article may be looked upon as commenting on the import of the conception of natural continua introduced by me in 1903,* though he makes no use of this notion itself.

There seems to be, however, little agreement in other respects. Professor Bôcher quotes one of my articles ("Das Apollonische Problem,” Mathematische Annalen, volume 49, 1897), merely stating that it is long and yet does not contain a word concerning the "region at infinity." $\dagger$ The first of these assertions is right as a matter of course, assuming a suitably chosen standard of length, and as to the second I will not quarrel with my critic. What I am concerned with is merely the inference which the author leaves to his readers. This inference would appear to be that I had been thoughtless, or careless, or regardless enough to publish my results in an embryonic state of development. It will inevitably be understood that all my theorems are "true in general" only, and consequently incorrect. I am found guilty of having committed an error to which, in recent years, I have myself objected often and strongly. I am caught in my own trap, and no mistake. There will be possibly some people who will enjoy this. But it cannot reasonably be expected that I should be one of their number. Therefore I beg to point out a few trifling circumstances that apparently have not been appreciated by my critic.

1. Let us supply the missing (but certainly indispensable)

* In my book, Geometrie der Dynamen, $\S \S 27,28$. This seems to have escaped Professor Bôcher's notice. He might have been aware of it, though, for he found a reference in connection with his own topic in a paper by $\mathrm{H}$. Beck.

$\dagger$ Bôcher's own term is "the infinite region." 
definitions, say, by the simple expedient of inserting a reference to Professor Bôcher's book of 1894. Then the haziness to which my critic objects will disappear at once and throughout. This remark, obvious as it is, does not seem to have occurred to Professor Bôcher; otherwise he ought to have mentioned it, for it alters the matter considerably. Probably he and I wrote for different sets of readers. I must, for some reason or other, have presupposed what Professor Bôcher explains. If my critic disapproves of this, it seems to me that he might have made clear the true trend of his objection, which is irrelevant, instead of making his readers believe that I had sinned against the first laws of logic, an intimation to which I cannot be indifferent. Professor Bôcher, who does not go far in the way of applications himself, might even have quoted my Apollonian paper as an illustration of the principles that underlie his doctrine; but, as a matter of fact, he meant to use it as a deterring example of their neglect, and only as such.

2. My fault (if fault it is) thus consisted in supposing notions widely known (and accepted by competent judges) which in reality perhaps were not so.* Why I held such an opinion is easily explained. The ideas in question are very simple. From the standpoint of Klein's Program of 1872 they appear almost as matters of course. To me they have been familiar since about 1884, the time when I was a young student under Professor Klein, who in later years was Professor Bôcher's teacher also, and to whom also Professor Bôcher, as he says himself, is indebted for the same ideas. It would seem to follow from this that the public I had in mind was likely to exist; and so it did, as is shown by the example of Professor Bôcher himself. But had it been nonexistent, I could still claim the right to write for it in the manner I did. What does not exist today may be common tomorrow. The first footnote in my paper shows that, notwithstanding its deplorable length, it is an extract only, and by no means intended for beginners.

3. I stated that I look upon the geometry of inversion as forming a counterpart (Seitenstück) to projective geometry (pages 498, 528), and I have treated it as such throughout. The idea apparently underlying Professor Bôcher's criticism,

* In my book of 1913 the point-continuum of the geometry of inversion is mentioned as a commonly accepted notion (page 282). 
that in spite of this attitude (which was opposed to the habits of my predecessors, Darboux, for example) I might have operated in this projective domain seems quite absurd.

4. A piece of research in projective geometry is not necessarily defective if its author does not speak of points at infinity. The same holds good for the geometry of inversion.

5. That my point of view was exactly the one recommended by Professor Bôcher can be conclusively demonstrated. I say (page 539): "Um diese Aufgabe (das Apollonische Problem auf der Kugel) zu lösen, haben wir weder in Formeln noch Constructionen auch nur die geringste Aenderung anzubringen." Then there must be a one-to-one correspondence between the plane I operated in (the "plane of inversion") and the sphere, without any exceptional points.

Finally a remark may be made that has nothing to do with the subject at variance. The terms region and points at infinity, though very convenient, are apt to cause misunderstandings. It should be noticed that the (euclidean) distance between a point "at infinity" and an ordinary point is not necessarily infinite. Under certain conditions, the investigation of which I leave to the reader, it is indeterminate. The similar terms used in projective geometry require a similar comment.

I do not care to follow Professor Study into the field of personal recrimination. Whether my article was calculated to be of use is neither for him nor for me to say. What it aimed to accomplish is clearly set forth in its first twelve lines, and this aim would not have been affected by the insertion, demanded by him, of a reference to his book. This reference would, however, as a matter of course have been made if I had been acquainted with the passage. The very brief allusion to the paper on the Apollonian Problem is the merest incident in the course of my article. In spite of Professor Study's remarks, the autobiographic part of which seems to me irrelevant, I see no substantial alteration which should be made in my words. I never said or implied, thought or wished the reader to think that this paper is too long. I do think it of sufficient length to warrant the expectation that the author should state explicitly and exactly what he was talking about. Various inferences, correct or incorrect, might be drawn from his failure to do so. I drew none.

MaXime Bôcher. 